\title{
Filmes brasileiros de mulheres paranóicas: as segundas mulheres e o horror no cinema brasileiro
}

\section{Laura Loguercio Cánepa}

\section{Resumo}

No âmbito das discussões sobre o horror no cinema brasileiro, tem-se como objetivo examinar aspectos do gênero presentes em cinco longas-metragens paulistas protagonizados por mulheres durante os anos 1950. Quer-se sugerir que tais obras, possivelmente inspiradas no que Mary Ann Doane (1987) chamou de "paranoid woman's films" hollywoodianos, podem ter tido alguma influência sobre filmes de horror brasileiros posteriores, entre os quais o seminal longa-metragem À meia-noite levarei sua alma (1964), do cineasta e ator paulista José Mojica Marins, tido como o primeiro e maior representante do gênero em nosso cinema.

Palavras-chave:

Cinema brasileiro. Filmes de mulher. Horror.
Laura Loguercio Cánepa | laura_canepa@yahoo.com.br Doutora em Multimeios pela Universidade Estadual de Campinas (Unicamp) I Docente do Mestrado em Comunicação da Universidade Anhembi Morumbi (UAM)

\section{Introdução}

Entre os raros estudos sobre o gênero

cinematográfico do horror no cinema brasileiro

- estes representados, sobretudo, pelas análises de recorte autoral da obra do cineasta/ator José Mojica Marins -, uma das questões que aparecem com frequência diz respeito às origens do gênero em sua versão nacional, isto é, ao seu nascimento oficial. Tradicionalmente, a crítica e a historiografia aceitaram a autoproclamação do próprio Mojica, em 1964, como realizador do primeiro filme de horror brasileiro, na ocasião da estreia de À meia-noite levarei sua alma, no qual encarnou pela primeira vez a figura do coveiro psicopata Zé do Caixão. Ocorre, porém, que essa versão dos fatos depende muito de como se encara a própria questão do cinema de gênero em nosso país, e tem merecido algumas revisões nos últimos anos.

Neste trabalho, pretendo trazer considerações em torno de filmes realizados pelos estúdios paulistas na década de 1950 que, ao dialogarem com alguns elementos do gênero horror encontrados de maneira dispersa em dramas psicológicos 
femininos hollywoodianos dos anos 1940, podem ter criado por aqui uma tradição "subterrânea" ligada, pelo menos, à primeira experiência de Mojica com o horror.

\section{Val Lewton, Hitchcock: as histórias de horror e os "filmes de mulher"}

Na década de 1980, quando os estudos sobre os gêneros cinematográficos ganhavam fôlego na crítica internacional, a teórica feminista Mary Ann Doane publicou o ensaio The desire to desire: the woman's films of the 1940's (1987), no qual examinava um grupo de filmes hollywoodianos pertencentes a diferentes gêneros (principalmente 0 melodrama familiar e 0 romance) que se caracterizavam por ter como protagonistas personagens femininas. Nas palavras de Doane (1987, p. 3), "0 rótulo filme de mulher se refere a um gênero produzido desde o cinema mudo até a década de 1960, mais concentradamente nas décadas de 1930 e 1940, quando conheceu maior popularidade”. Segundo ela, esses filmes de mulher seriam um campo de análise privilegiado para a crítica feminista, pois colocavam em primeiro plano tanto a subjetividade feminina mediada pelo cinema quanto as próprias mulheres espectadoras.

Tal grupo de filmes, tido pelos produtores como um gênero específico voltado às audiências femininas, poderia ser definido como "um tipo de obra que tem como centro de seu universo narrativo uma personagem que deve lidar emocional, social e psicologicamente com problemas específicos derivados do fato dela ser mulher" (NEALE, 2000, p. 189). Tal pretensão narrativa fazia com que, pelo menos naquela época, a maior parte desses filmes estivessem ligados aos temas das esferas doméstica, familiar e amorosa heterossexual, privilegiando o elogio ao amor materno, a pacificação do lar, a fidelidade amorosa e 0 autossacríficio das mulheres em nome da preservação da família ou do status quo patriarcal.

Mas, junto desses filmes, Doane observa a existência de um híbrido muito comum, o qual denominou de "paranoid woman's film" (ou "filme de mulher paranóica"). Tratava-se, segundo ela, de um tipo de obra com temática feminina feita nos moldes do thriller de mistério e do filme de horror - gêneros que, como demonstra Jankovich (2007, tradução nossa, grifos nossos), eram, naquela época, frequentemente tratados como sinônimos: -

0 uso dos termos filme de horror e thriller nas críticas dos anos 1940 demonstram que eles não eram vistos como categorias genéricas distintas. [...] Assim, muitos filmes comumente entendidos hoje como sendo thrillers eram identificados como de horror naquele tempo, e vice-versa. Além disso, o termo thriller não era diretamente associado à ação ou ao suspense, mas sim a certas sensações e medos ligados a certas formas de horror. Não se trata aqui de defender que certo grupo de filmes pertença de fato a uma ou outra categoria, mas sim de explorar os caminhos que essas formas genéricas seguiram durante os anos 1940 e, nesse processo, demonstrar que muito do que hoje chamamos de filmes de mulheres paranóicas e filmes noir podem ser vistos como um ciclo mais extenso do gênero horror daquele período. 
Conforme a descrição de Doane, nos filmes de mulheres paranóicas, a instituição do casamento se encontra literalmente assombrada pela ideia do assassinato. De maneira geral, essas estórias têm início quando jovens mulheres recém-casadas começam a imaginar que seus maridos desejam matá-las - e encontram pistas disso por toda a casa ameaçadora em que passam a viver (D0ANE, 1987, p. 123). Helen Hanson (2007, p. 67-68) destaca que a narrativa básica desses filmes costuma incluir a seguinte sequência de eventos: o rápido romance entre uma jovem e um homem muito mais velho; a cerimônia do casamento representada sem grande destaque, como um mero rito de passagem para a heroína; a suspeita sobre o comportamento do marido com a chegada na nova casa; a investigação sobre o relacionamento do homem com uma outra mulher; a descoberta de um segredo do passado; o confronto ou a confissão; a resolução, muitas vezes (mas nem sempre) apaziguadora do casal.

Doane (1987, p. 134) classifica esses filmes como "paranóicos" porque o sentimento de ameaça vivido pelas mulheres é colocado sob suspeita durante maior parte do tempo, estando sujeito a uma longa investigação que deverá verificar a validade do olhar feminino - a essas alturas, levado quase à loucura pela dúvida e pelo medo. Para a autora, nesses filmes, a inferioridade psicológica e social da mulher é o maior motivo de seu terror, 0 que faz com que, não raro, seu corpo acabe sendo motivo de um interesse médico que vê seu medo como sintomático de algum problema psiquiátrico.
Mas, como pontua Jankovich (2007), também não é raro que, nesses filmes, a loucura da mulher seja representada como resultado de uma personalidade masculina patológica e às vezes monstruosa, fazendo com que o processo de investigação acabe por dar razão à sua desconfiança. Para Thomas Elsaesser (1973 apud HANSON, 2007, p. 40), que batizou esse ciclo de filmes como "melodramas freudianos femininos", as fantasias de perseguição, estupro e morte - sejam elas devaneios masoquistas das mulheres ou não - lançam seus maridos no papel de assassinos sádicos, transformando suas esposas não apenas em vítimas, mas em heroínas corajosas, capazes de seduzi-los e desmascará-los. Nesse sentido, tais filmes fazem paralelo ao gênero do mesmo período centrado em detetives do sexo masculino que depois ficaria conhecido como film noir. Tanto assim que ambos os gêneros usaram com frequência o recurso estilístico da narração em primeira pessoa, o que, juntamente com a ação preferencialmente noturna e com a grande quantidade de personagens moralmente ambíguos, só reforça a relação entre eles.

No que tange ao gênero horror propriamente dito, o franco irracionalismo e o medo constante da morte, aliados a uma representação que não raro sugere 0 sobrenatural e 0 fantasmagórico, denunciam a filiação desses filmes a uma linhagem cujas origens narrativas podem ser encontradas na literatura gótica, e as origens visuais, no cinema expressionista alemão. Aliás, não é mera coincidência que importantes 
diretores, roteiristas e fotógrafos europeus, e sobretudo alemães (Fritz Lang, Otto Premminger e Robert Siodmak, por exemplo) tenham estado presentes em muitas dessas produções.

No começo da década de 1940, o primeiro ciclo hollywoodiano de horror, conhecido como "Universal Gothic" (pois foi praticado principalmente nos estúdios da Universal, que haviam trazido o cineasta alemão Paul Leni ${ }^{1}$, no final dos anos 1920, para coordenar projetos nesse sentido) via seus monstros masculinos clássicos - Drácula, Frankenstein, A Múmia, Lobisomem - entrarem em franca decadência. Esse ciclo, que fora definitivo para a consolidação do gênero horror e do próprio cinema B, seria substituído por outro, encabeçado pelos estúdios da RKO e liderado pelo cineasta e produtor ucraniano Val Lewton, trazendo, no lugar dos monstros clássicos, mulheres mentalmente perturbadas em papéis centrais.

0 primeiro filme do ciclo Val Lewton foi Sangue de pantera (Cat people, Jacques Tourneur, 1942), no qual um homem se casa com uma imigrante romena que acredita ser dominada por uma maldição que a transforma numa pantera assassina quando faz sexo. Este filme teria uma continuação, A Maldição do Sangue de Pantera (The curse of the cat people, Günter Von Fritsch e Robert Wise, 1944), no qual a mesma maldição passa a assombrar uma menina. Outros filmes desse ciclo foram A Morta Viva (I walked with a zombie, Jacques Tourneur, 1943), no qual uma enfermeira vai para 0 Haiti cuidar de uma mulher supostamente cataléptica, e $A$ sétima vítima (The seventh victim, Mark Robson, 1943), sobre uma mulher que sai à procura da irmã sequestrada por uma seita satânica.

0 ciclo da RKO teve vida relativamente curta, encerrando-se em 1946, mas exerceu um papel fundamental no sentido de modernizar e trazer novos temas para 0 gênero, além de representar, com seu baixo custo e grande sucesso de público, uma tábua de salvação financeira para 0 estúdio, que vinha de dois grandes fracassos comerciais (a despeito do inquestionável sucesso artístico): Cidadão Kane (Orson Welles, 1941) e Fantasia (Walt Disney, 1940).

Ao lado desse ciclo voltado ao mercado B, produtores e diretores como David 0. Selznick, Alfred Hitchcock, Fritz Lang e outros realizaram thrillers de horror e mistério com protagonistas do sexo feminino, dando origem ao grupo específico de filmes femininos paranóicos observados por Doane, entre os quais se destacam Rebecca - a mulher inesquecível (Rebecca, Alfred Hitchcock, 1940, que teve participação de Val Lewton no roteiro e na edição), ’̀ meia-luz (Gaslight, George Cukor, 1944), Silêncio nas 
trevas (The spiral staircase, Robert Siodmak, 1945), Inspiração Trágica (The two Mrs.

Carrolls, Peter Godfrey, 1947), O segredo atrás

da porta (The secret beyond the door, Fritz Lang, 1948) e vários outros.

Tais filmes, apesar do paralelo evidente com as tramas de detetives depois chamadas de noir, também vinculavam as estórias de crimes e mistérios vividos por mulheres a uma tradição mais antiga: a da literatura gótica europeia, derivada de um estilo literário nascido na Inglaterra século XVIII e tido justamente como inaugurador tanto do moderno gênero horror quanto do policial - mas que, por ter sua origem coincidente com o melodrama, caracterizou-se desde 0 início pelo interesse no feminino, trazendo mulheres como personagens, leitoras assíduas e até escritoras, entre as quais figuraram Ann Radcliffe e Regina Maria Roche, no final do século XVIII, e Mary Shelley e as irmãs Emile e Charlotte Bronté, no século XIX.

Tendo surgido num período particularmente crítico da história do 0cidente, o gótico e 0 melodrama têm vários pontos em comum, como 0 maniqueísmo, a desconfiança em relação aos personagens aristocráticos, a relação ambígua com a natureza (ameaçadora ou idealizada, conforme o caso) e um evidente exagero na representação. Outro ponto comum é a recorrência de alguns temas específicos, entre eles o das mulheres que, em razão de algum infortúnio, vão parar nas mãos de perigosos proprietários de terras ou religiosos que as mantêm presas a alguma uma tradição cruel.

Especificamente, como define Hoggle (2002, p. 2), uma estória gótica acontece num espaço antigo e tradicional no qual se escondem violentos segredos que assombram os personagens tanto psicológica quanto fisicamente. A frequência com que tais personagens acuados pertencem ao sexo feminino é tanta que Mary Ann Doane (1987, p.124) chega a citar a fórmula de Leona Sherman que iguala 0 gótico à "imagem da mulher-maishabitação". Como Doane, Jankovich e outros já apontaram, a relação dos filmes femininos paranóicos com a tradição gótica é evidente. A análise de Vanoye e Golliot-Letté (1994, p. 130) para Rebecca, tido por Doane como "inaugurador" da tendência, demonstra isso:

Rebecca pertence à tradição do filme gótico: a narrativa se desenvolve em grande parte num solar antigo cujas paredes trazem a marca de um passado longínquo e perpetuam a lembrança daqueles que lá viveram. A disposição dos cômodos, a importância desse ou daquele cômodo em detrimento de outro, o vínculo entre natureza e certos eventos e 0 local onde se desenvolvem, tudo isso é primordial em Rebecca e refere-se à organização do espaço do gótico.

Essa ligação com a tradição gótica seria explorada pelos filmes no período. Segundo Hanson (2007, p. 45), os materiais promocionais dos filmes de mulheres paranóicas (que ela prefere chamar de "góticos femininos") aproveitavam a popularidade de suas fontes literárias, distribuindo pressbooks nas sessões de cinema e incentivando editores 
a explorarem as ligações entre livros e filmes em atividades como grupos de leitura, além de criar cartazes e outros produtos que revelassem 0 potencial dessa relação. Também vale lembrar que, antes do filme, Rebecca já havia sido serializado em folhetins e encenado pelo Welles Meecury Theather, dirigido por Orson Welles, em Nova Iorque, em 1938, marcando um ciclo que viria acompanhado de montagens dos clássicos góticos do século XIX O Morro dos Ventos Uivantes e Jane Eyre, de Emile e Charotte Bronté.

\section{Paranoid woman films no Brasil: na trilha das segundas mulheres}

Nos anos 1950, com as mudanças ocorridas no pós-guerra nos EUA, os filmes de mulher já se apresentavam de maneira um pouco diferente, $\mathrm{e}$ os filmes de mulheres paranóicas pareciam um filão quase esgotado. Mas, no cinema brasileiro, tal configuração teve destaque exatamente nessa década, nos filmes produzidos pelos maiores estúdios paulistas, conforme descreve Ismail Xavier (2003, p. 171):

No contexto da produção paulista da época, [tentou-se] transplantar certo clima típico de uma tradição ficcional soturna em que jovens burguesas são retiradas de seu 'mundo natural' pelo casamento [...] com homens ricos, e são projetadas num mundo hostil de fantasmas do passado que as ameaça.

0s filmes que resultaram dessa tendência não podem ser classificados como de horror, já que sua matriz mais evidente é o melodrama centrado em figuras femininas sofredoras, mas há, neles, elementos que indicam a temática incipiente do horror a partir da tradição gótica e dos filmes de mulheres paranóicas. São eles: Caiçara (Adolfo Celi, 1950) e Veneno (Giani Pons, 1952), da produtora Vera Cruz; Meu Destino É Pecar (Manuel Peluffo,1952), da Maristela; Chamas no Cafezal (José Carlos Burle, 1954), da Multifilmes; Estranho Encontro (Walter Hugo Khouri, 1957), da Brasil Filmes. Porém, esses filmes de mulheres brasileiras paranóicas não têm relação apenas com a tendência hollywoodiana ou com a literatura estrangeira. Num sentido mais especificamente brasileiro, eles também dialogam com uma tradição nacional de estórias sobre "segundas mulheres" que, como nota Ana Lúcia Enne (2008), configuram um tema recorrente na nossa cultura.

Como descreve Enne (2008, p. 1), desde o final do século XIX, repetem-se, na nossa ficção literária, romances em que a protagonista é uma segunda mulher obrigada a enfrentar 0 fantasma da primeira esposa, já falecida, mas ainda reinante dentro do lar, por vezes no coração do marido e quase sempre na memória daqueles que com ela conviveram. Tal plot não era inédito, mas tornou-se particularmente ressonante na produção ficcional brasileira, inclusive nos folhetins radiofônicos e televisivos, especialmente na primeira metade do século XX.

Nesse contexto, pode-se destacar quatro romances publicados no Brasil entre 1878 e 1944 que trazem o tema da "segunda esposa" como questão central, sendo que três deles o fazem dentro da 
tradição da ficção gótica: Encarnação (1878), de José de Alencar; A Intrusa (1905), de Júlia Lopes de Almeida; A Sucessora (1934), de Carolina Nabuco; Meu destino é pecar (1944), de Susanna Flag (pseudônimo de Nelson Rodrigues, que então estreava no gênero romance/folhetim).

0 primeiro, escrito por um de nossos mais importantes romancistas e publicado postumamente, trazia alguma influência do espiritismo que então começava a chegar ao Brasil. Encarnação contava a estória de Amália, jovem que se casa com o viúvo Carlos, ainda obcecado por Julieta, sua primeira mulher que morrera durante a gravidez do primeiro filho. Ao acreditar-se impotente diante de um amor que domina morbidamente toda a casa (e um quarto em particular) e também a imaginação do marido e dos empregados (sobretudo Abreu, um velho serviçal), Amália começa a anular-se, até que um incêndio supostamente provocado pelo fantasma de Julieta destrói a velha casa e liberta os amantes - que acabam tendo uma filha tão parecida com a primeira mulher de Carlos, que acaba herdando seu nome.

Mais de 20 anos depois, $A$ Intrusa retomaria 0 tema da segunda mulher, mas evitaria as sugestões fantásticas, trazendo a jovem Alice, oriunda de família tradicional, porém falida, que usa a sua sólida formação educacional para trabalhar na casa de um viúvo rico, Argemiro, e ajudá-lo a cuidar de sua filha adolescente, a rebelde Glória. Com dedicação ao lar e muito trabalho, Alice acaba por conquistar 0 viúvo, apesar da promessa de amor eterno que este fizera à primeira mulher, e a despeito da antipatia da sogra, uma baronesa decadente que vê Alice como uma ameaça à sua família, e de Feliciano, empregado que dominava a casa antes da chegada de Alice.

Outros 30 anos se passaram, e então Carolina Nabuco, criou, em A Sucessora, um amálgama das duas estórias anteriores. Seu romance retomava, embora de maneira muito mais discreta, a atmosfera "espírita" de Encarnação, tratando de Marina, (mais uma) jovem que se casa com um rico viúvo e começa a ser atormentada pelo retrato de sua falecida esposa, Alice (nome da heroína de $A$ Intrusa), que a faz sentir-se insegura, diminuída e às vezes amedrontada, especialmente pelas referências constantes de empregados, parentes e do próprio marido à falecida.

Descendente de fazendeiros decadentes, Marina passa a oscilar entre um ex-noivo sensível, porém fracassado e representante do que a própria personagem chamava de "velho Brasil", e a nova vida junto à alta burguesia à qual pertence seu galante marido, Roberto, e à qual Alice era muito bem integrada. No final da história, Marina engravida e tudo se acalma, pois ela consegue dar ao marido a única coisa que sua antecessora não conseguira.

0 livro seria supostamente plagiado pela inglesa Daphne Du Maurier, em 1938, ganhando o título de Rebecca, tornando-se best-seller mundial e virando filme de Hitchcock em 1940. Em Rebecca, 
a heroína sem nome é uma jovem órfã que se casa com um aristocrata que é dono de um enorme solar antigo (Manderlay) e é viúvo da misteriosa Rebecca, amada pelos empregados, sobretudo pela sinistra governanta Mrs. Danvers. Apesar da semelhança com o romance de Nabuco, Rebecca traz uma diferença fundamental: 0 assassinato da primeira mulher pelo marido, elemento suavizado no filme, mas não ignorado completamente.

Então, possivelmente sob a influência do sucesso de Rebecca e da polêmica surgida no Brasil em relação ao possível plágio de $A$ Sucessora, Nelson Rodrigues lançaria o folhetim Meu Destino É Pecar, em 1944, no jornal Correio da Manhã. A obra fez um enorme sucesso, com milhares de exemplares vendidos diariamente, depois publicados em livro e adaptados para o rádio. $\mathrm{Na}$ verdade, parecia tratar-se de um escárnio (embora não percebido assim pela maioria dos leitores) do estilo e da trama de Nabuco, Du Maurier e outras autoras, acrescido de mausoléus, macumba, erotismo e altas doses de sensacionalismo. Em Meu Destino É Pecar, a jovem pobre e feia Leninha é obrigada pela família a se casar com um viúvo aleijado e bêbado, Paulo, e a morar com sua família numa fazenda decadente. Lá, ela toma contato com as memórias da primeira mulher de Paulo, a bela Guida, que morrera atacada pelos ferozes cães do marido e cujo fantasma supostamente circula pela casa à noite. Desconfiada de que Paulo pode ter assassinado Guida, Leninha acaba sendo acolhida pela soturna prima Lídia, apaixonada pelo irmão de Paulo, o cafajeste Maurício. À medida que as tramas se esclarecem, fica evidente que Lídia fora a assassina de Guida por ciúmes de um suposto caso com Maurício, e Leninha, apaziguada, consegue se aproximar do marido e finalmente e dar-lhe o filho desejado por todos.

Enne (2008) procura relacionar os romances Encarnação, A Intrusa e A Sucessora ao processo de modernização do Brasil, o que incluía a instrução feminina, a geração de descendentes, as mudanças na administração do lar. Sem dúvida, tais questões são evidenciadas nos romances, sobretudo em A Sucessora, que as verbaliza muito claramente. Mas o caminho pretendido pelo presente trabalho não é este, e sim a discussão sobre a tradição do romance gótico que pode ser encontrada a partir de Encarnação.

\section{Sucessoras em abismo: 0 affair Rebecca}

A obra de Carolina Nabuco não ficou muito conhecida no Brasil, mas, quando o livro de Du Maurier virou best-seller mundial, a polêmica em torno do plágio gerou alguma repercussão, levando Monteiro Lobato a rapidamente traduzir o livro. A questão se complicou mais quando chegou ao Brasil, em 1941, o filme do diretor inglês Alfred Hitchcock, Rebecca - A mulher inesquecivel. Segundo Carolina Nabuco (2000, p. 140-141):

Quando o filme Rebecca chegou ao Brasil, o advogado de seus produtores (United Artists), doutor Alberto Torres Filho, procurou meu advogado, Bartolomeu Anacleto, para pedir-lhe que eu me prestasse a assinar um documento admitindo a possibilidade de ter havido mera 
coincidência. Se me prestasse a isso, eu seria compensada com uma quantia que 0 doutor Torres qualificou como 'de ordem patrimonial'. Não anuí, naturalmente.

Nesse mesmo período, os filmes de mulheres paranóicas e os de Val Lewton faziam sucesso no Brasil entre críticos e cinéfilos, como já declararam cineastas que fizeram sua formação nesse período, como Walter Hugo Khouri, Rubem Biafora e Maximo Barro². Provavelmente não por acaso, seis anos depois, com a abertura dos estúdios paulistas, surgiram os filmes brasileiros em questão nesta pesquisa.

Já no primeiro filme da Vera Cruz, Caiçara, dirigido por Adolfo Celi e corroteirizado por ele e Alberto Cavalcanti, há uma relação discreta entre o melodrama e o horror das mulheres paranóicas, embora a referência mais direta do plot seja ao drama Stromboli (Itália, 1950), realizado por Roberto Rosselini. No filme, a jovem Marina, interpretada por Eliane Lage (e que curiosamente recebeu o nome da heroína de A Sucessora), vive num internato de moças onde fora deixada pelos pais leprosos. De lá, é levada como esposa por Zé Amaro (Carlos Vergueiro), um viúvo que trabalha como construtor de barcos pesqueiros numa certa Ilha Verde. Na ilha, Marina percebe que seu marido é um alcoólatra violento (como o marido de Meu Destino é Pecar) e começa a sofrer com 0 assédio do sócio dele, Manoel (como o cunhado da trama de Nelson Rodrigues). Então, ela se aproxima do menino Chico, neto da mãe- preta Sinhá Felicidade, que acusa o ex-genro Zé Amaro de ter provocado a morte de sua filha. A mãe-preta passa a proteger Marina por meio de rituais de magia que incluem danças, rezas e um tipo de vudu. Porém, uma sequência de mortes violentas começa a acontecer na trilha dos rituais de Sinhá, vitimando Zé Amaro, Manoel e o menino Chico. Apesar dessa tragédia, os caminhos ficam abertos para Marina finalmente encontrar o amor verdadeiro nos braços do marinheiro Alberto (Mário Sérgio), que se apaixona por ela. Segundo Galvão (1996, p. 89):

0 que ocorre em Caiçara é uma exaltação neo-romântica do caráter irracional do povo brasileiro: observa-se este lado demoníaco para domesticá-lo. A mãe preta. conduz o destino dos personagens como de modo a eliminar 0 mal da sociedade e possibilitar o caminho reto do progresso, liderado, agora, por uma burguesia conseqüente, de bom coração e que sabe amar.

Caiçara nunca foi visto como um filme ligado ao horror, e sua locação na luminosa também não 0 relaciona diretamente com a tradição gótica. Mas é preciso lembrar que, no começo dos anos 1950, o horror cinematográfico assim chamado, além de estar calcado nas histórias com monstros, não constava entre os gêneros "classe A" de Hollywood ou dos estúdios europeus - e, nesse sentido, não podia estar nos horizontes da Vera Cruz. Porém, do ponto de vista do temário clássico do horror, Caiçara pode ser ligado parcialmente ao gênero, pela habilidade com que lida com aspectos sobrenaturais e violentos, usando- 
os narrativamente com o objetivo de sugerir poderes malévolos implacáveis. Nesse sentido, não parecem descabidas as ligações entre Caiçara e uma herança difusa do imaginário gótico adaptada às crenças religiosas brasileiras (CANEPA, 2008, p. 203).

Outra obra ainda mais significativa foi

Meu destino é pecar, primeira adaptação

cinematográfica de Nelson Rodrigues, escrita por Manuel Pelluffo, Carlos Ortiz e Alferdo Palácios. A trama do filme de Manuel Pelluffo é relativamente fiel ao livro (levando-se em conta as dificuldades de adaptação de um imenso folhetim), e explora 0 imaginário de sombras, escuridão e mausoléus. 0 filme também tenta fazer da intérprete de Lídia, Zilah Maria, uma réplica brasileira da terrível Mrs. Danvers, interpretada por Judith Anderson em Rebecca.

A obra não foi bem recebida pelos críticos, que se mostraram insatisfeitos com as más atuações, com o tom sensacionalista e com 0 tipo de evocação (supostamente canhestra) da atmosfera de horror. Mas o filme também não desagradou totalmente a Nelson Rodrigues, gerando até mesmo uma curiosa história contada por Heffner, e que atesta mais uma vez a importância dos filmes de horror com mulheres para a compreensão dos filmes brasileiros dos anos 1950 e mesmo do folhetim Meu destino é pecar:

Nelson adorava as obras de Val Lewton, provavelmente por seu caráter gótico, e por isso
Meu Destino È Pecar não o desagradou de todo. Escondido sob o pseudônimo de Mabert, ele escreve no Diário da Noite (11/01/1952) uma apresentação bastante elogiosa e publicitária. Mas, ao ver o filme em primeira mão nos estúdios da Maristela, Nelson cumpre o ritual: deixa bastante claro que gostou de duas coisas - a fotografia de Mario Pagés e a atuação de Zilah Maria, 'a louca'. (HEFFNER, 1994, p. 19)

Outro filme que recuperou matrizes góticas e tramas de mulheres paranóicas foi Chamas no cafezal (1954), de José Carlos Burle. Como descreve Maximo Barro, "[...] a trama era centrada nos incidentes [...] [causados pela] sombra da falecida primeira esposa que rondava a casa através de retratos retirados das paredes, quartos trancafiados, matagais intocáveis, negras velhas com frases equívocas." (BARR0, 2007, p. 261).

0 filme tematizava a crise da aristocracia cafeicultora através da história de Angélica (Angélica Hauff), uma carioca recém-casada com o agricultor paulista Anésio (Guido Lazzarini). Ao chegar à sua nova casa, ela descobre que esta foi reivindicada por um banco e que Anésio, apesar de possuir uma fazenda potencialmente produtiva, a mantém repleta de segredos e de lugares proibidos, num pacto autodestrutivo com 0 passado. Então ela decide romper o ciclo de decadência ao descobrir o segredo que, para o marido, amaldiçoara a fazenda: anos antes, ele havia se apaixonado por uma empregada, engravidando-a e obrigando seus pais a aceitarem o casamento, mas vira todos morrerem num acidente de carro no meio da mata que cercava a fazenda, no dia das bodas, sentindo-se para 
sempre culpado e maldito. Em sua obsessão sinistra, Anésio mantinha todas as sobras da festa de casamento junto ao túmulo da amada, no meio da mata que ameaçava o cafezal. Angélica decide colocar fogo na mata (mais ou menos como ocorre em Rebecca) e consegue devolver a razão ao marido.

Outros dois longas-metragens dos estúdios paulistas também se interessaram pelo triângulo formado por um homem misterioso, sua primeira mulher ou amante e sua sucessora, embora não tenham tido como principal foco de interesse a figura da segunda mulher.

0 primeiro deles é Veneno (1952), dirigido e escrito pelo italiano Gianni Pons e fotografado em estilo noir por Edgar Brasil. 0 filme trata de alucinações e premonições malignas através da figura de Hugo (Anselmo Duarte), um industrial e marido infeliz, que começa a ter pesadelos nos quais mata sua esposa, a femme fatale Gina (Leonora Amar). Nesses pesadelos, ele sempre é interrogado por um delegado de polícia (Ziembinski) que, um dia, acaba indo realmente à sua casa perguntar sobre um assalto, o que faz com que Hugo passe a acreditar que seus sonhos são premonitórios. Então, ele conhece Diana (Leonora Amar), uma cantora de cabaré que é sósia perfeita de Gina. Por causa desse encontro, ele acaba chegando em casa muito tarde e, ao ser repreendido pela mulher, dá a ela um veneno no lugar de remédio, matando-a. Então, ele abandona o corpo de Gina num terreno perto de uma ferrovia, simulando um suicídio e, em seguida, convida Diana para viver com ele, sem dizer a ela que pretende apenas despistar os vizinhos. A moça aceita o convite, mas percebe que há algo de errado com seu novo amante, e começa a investigar sua vida, acabando por descobrir 0 segredo aterrador. Acuado pela polícia, Hugo corre para a ferrovia, onde tem uma visão das mãos de Gina, que o chamam para baixo da terra, e ele acaba sendo atropelado por um trem.

Em Veneno, como nos filmes anteriormente citados, uma elite decadente (no presente caso, muito mais rica e moderna, e não apenas privilegiada no microcosmo representado) também é destruída pela irracionalidade, pela violência e por coincidências que mais parecem maldições. Também a proposta visual do filme fazia claras referências a um "gótico urbano" que então já era observado nos filmes noir, nos quais as mulheres fatais e as investigações policiais também estavam sempre presentes.

Já em 1958, seria a vez de Walter Hugo Khouri trazer uma trama bem mais complexa, mas que apresenta traços dos filmes anteriores. Estranho Encontro também ganha particular importância por já sugerir seu interesse por temas do horror, que ele retomaria nos anos 1970. A estória, escrita pelo próprio diretor, misturava romance e terror psicológico: numa noite na estrada, um rapaz que vive como gigolô (Mário Sérgio) salva uma jovem (Andréia Bayard) que fugia das garras de um misterioso sádico (Luigi Picchi) com quem 
se envolvera. Ele decide escondê-la na casa de campo de sua amante de quem deseja separarse (Lola Brah), onde acaba sofrendo um triplo assédio: do maníaco que persegue a jovem, da dona da casa vingativa e também do seu sinistro mordomo (Sérgio Hingst). 0 filme se passa a maior parte do tempo num casarão isolado e quase vazio, o que cria uma atmosfera gótica, reforçada pela presença de um vilão com características psicológicas incomuns. Nesse sentido, embora não proponha exatamente um triâgulo (visto que são quatro os amantes envolvidos na história), o filme propõe uma trama de mulheres sendo substituídas sob o encalço de um homem violento.

Estranho encontro foi lançado nos cinemas em maio de 1958. A fita foi bem recebida entre os críticos, mas ajudou a criar uma avaliação especial sobre Khouri: a de que se tratava de um cineasta hábil e sofisticado, porém preocupado demais com elucubrações pessoais e pouco afeito ao debate sobre os problemas sociais e culturais específicos que então já movimentavam o cinema do país (CANEPA, 2008, p. 220). Apesar de não disfarçar a insatisfação com a concepção do filme de Khouri, supostamente deslocada da realidade brasileira, Paulo Emílio Salles Gomes (1981, p. 353-354) seria bastante arguto em suas observações sobre 0 seu clima de mistério:

Segundo suas expressas declarações, toda a primeira parte, 0 encontro de Marcos com a moça na estrada, a instalação de ambos na casa de Vanda, até a chegada da proprietária, deveria constituir um acontecimento lírico. $\mathrm{Na}$ realidade, 0 tom que domina é 0 de mistério, particularmente nas admiráveis sequiências em flashback que se iniciam na relojoaria $\mathrm{e}$ nas quais visualiza-se a narração da heroína. A partir daí, o realizador domina essa espécie de rebelião do estilo contra a sua vontade, mas 0 espectador se sente um pouco perplexo.

\section{0 triângulo maldito revisitado por Mojica}

Em 1952, Veneno já indicava um caminho mais claro dos filmes de mulheres paranóicas em direção ao horror, quando escolhia como principal foco narrativo o marido psicótico, provocando suspense quando acompanhamos os fatos que levam ao assassinato da primeira esposa e à tentativa de assassinato da substituta. 0 fato desse filme não ter "feito escola" não empalidece sua importância como um dos precursores do horror cinematográfico brasileiro. Mas, 12 anos depois, o triângulo marido-misterioso + primeiraesposa-sem-filhos + segunda-esposa-jovem encontraria no longa-metragem Á meia-noite levarei sua alma, de José Mojica Marins, sua verdadeira "vocação" para o horror.

No filme, temos 0 agente funerário Josefel Zanatas, conhecido como Zé do Caixão, às voltas com o desejo de ter um filho que possa "dar continuidade ao seu sangue". 0 problema é que sua infeliz esposa, Lenita, não consegue engravidar. Decidido a resolver seu problema usando quaisquer artifícios, ele mata sua esposa, alegando que uma mulher que não pode ter filhos não precisa viver, e sai à caça de uma sucessora - mesmo que para isso precise estuprar e matar. 
A escolhida, Terezinha, violentada por Zé, acaba se suicidando, mas não sem antes jurar que sua vingança virá do além. Então, numa noite em que todos os habitantes da cidade evitam sair de suas casas com medo da "procissão dos mortos", Zé decide sair com uma moça recém-chegada. No caminho, uma cigana anuncia que o destino de Zé estará selado se ele não voltar para casa antes da meia-noite. 0 coveiro não acredita, mas, na volta, é abordado pelos mortos em procissão. Zé corre pelo mato até refugiar-se no cemitério, onde se depara com os cadáveres de suas vítimas. Apavorado, é encontrado morto pelo povo.

É curioso notar que Mojica, ao estrear 0 horror no cinema brasileiro supostamente sem se relacionar com qualquer antecedente cinematográfico (como ele próprio e os críticos sempre propagaram), possivelmente sem perceber, retomou o triângulo (pouco) amoroso dos filmes brasileiros de mulheres paranóicas da década anterior, explicitando o problema da descendência e do autoritarismo masculino numa representação mais obviamente violenta $\mathrm{e}$ aterradora. Mesmo que a estória contada no filme tenha sofrido outras influências mais diretas, inclusive de própria vida pessoal de Mojica (consta que sua então esposa não conseguia ter filhos), parece evidente que os filmes dos estúdios paulistas no mínimo apontavam para a ressonância do tema na ficção brasileira, servindo como uma das fontes originais de nosso cinema de horror.
A saga de Zé do Caixão à procura de uma sucessora fértil para Lenita continuaria nos dois filmes seguintes da série (Esta noite encarnarei no teu cadáver, de 1967, e Encarnação do demônio, de 2008), mas o tema das segundas mulheres também permaneceria presente no horror brasileiro, ainda que o personagem masculino tenha ficado bastante enfraquecido sob a sombra da maldade do coveiro psicopata. Pode-se observar a recorrência das segundas mulheres no cinema de horror brasileiro da década de 1970 em filmes de Walter Hugo Khouri e Carlos Hugo Christensen centrados em figuras femininas envolvidas com terrores do passado: As Filhas do Fogo (Khouri, 1970), no qual uma filha se vê assombrada pelo fantasma da própria mãe; A Mulher do Desejo (Christensen, 1975), em que uma mulher é reencarnação de uma suicida; Enigma para Demônios (Christensen, 1975), no qual uma mulher é vítima do mesmo ritual satânico que matara sua mãe. Também há que se destacar uma versão cinematográfica de Encarnação (1978), dirigida por J.B. Marreco, e o curioso Estrela Nua, de Ícaro Martins e Zé Antonio Garcia (1986), no qual uma atriz que substitui uma suicida na dublagem de um filme passa a ser assombrada pelo espectro da outra. Nesses filmes, continuam em evidência as mulheres jogadas em cenários antigos e às voltas com segredos que envolvem suas antecessoras na vida, no trabalho ou mesmo em outras encarnações - 0 que sugere uma certa "trilha" temática no desenvolvimento da ficção de horror no cinema nacional. 
Dentro das discussões sobre as configurações dos gêneros no cinema brasileiro, um dos maiores problemas enfrentados pelos teóricos e historiadores é uma certa tendência a isolar o cinema das outras mídias e mesmo de obras cinematográficas estrangeiras, o que cria uma falsa ideia de isolamento do cinema brasileiro em relação ao seu contexto. No entanto, análises como a que proponho aqui em relação a um gênero específico, ainda que iniciais, permitem que pensemos em outros olhares para os processos culturais mais amplos registrados pelo nosso cinema, e que também apontam para a complexa dinâmica da conformação dos gêneros narrativos adotados pelas mídias audiovisuais no Brasil.

\section{Referências}

BARR0, Máximo. José Carlos Burle - Drama na Chanchada. São Paulo: Imprensa Oficial do Estado de São Paulo, 2007. (Coleção Aplauso)

\section{CANEPA, Laura Loguercio. Medo de quê? - Uma}

\section{História do Horror nos Filmes Brasileiros.}

Tese (Doutorado em Multimeios) - Instituto de Artes, Universidade de Estadual de Campinas, Campinas, 2008.

DOANE, Mary Ann. The Desire to desire: the woman's films of the 1940's (Theories of representation and difference). Bloomington: Indiana U.P., 1987.

ENNE, Ana Lúcia. Romances de segunda esposa: o Brasil entre a tradição e a modernidade. In: ENCONTRO DA COMPÓS, 17., 2008. São Paulo.
Anais... São Paulo: Compós, 2008.

GALVÃo, Maria Eliezer. A Vera Cruz e Caiçara: uma alegoria da nação brasileira. Cinemais Revista de Cinema e outras questões audiovisuais, Rio de Janeiro, n. 1, p. 83- 102, set. 1996.

HANSON, Helen. Hollywood heroines: women in film noir and the female gothic. Londres; Nova Iorque: I.B.Tauris, 2007.

HOGGLE, Jerrold E. (Org). The Cambridge companion of gothic fiction. Edimburgo:

Cambridge University Press, 2002.

JANKOVICH, Mark. Crack-up: psycologichal realism, generic transformation and the demise of paranoid woman films. The Irish Journal of Gothic and Horror Studies, n. 3, nov. 2007. Disponível em: http://irishgothichorrorjournal. homestead.com/Crack-upJancovich.html Acesso em: 02 fev. 2010.

NABUCO, Carolina. Oito décadas - Memórias. Rio de Janeiro: Livraria José Olympio Editora, 2000.

NEALE, Steve. Genre and Hollywood. Londres: Routhledge, 2000.

HEFFNER, Ernani. Nelson Rodrigues e 0 cinema. In: PUPPO, E; XAVIER, I. (Org.). Nelson Rodrigues e o cinema. Rio de Janeiro: Centro Cultural Banco do Brasil, 2004, p. 19-20.

GOMES, Paulo Emílio Salles. Rascunhos e exercícios. In: Crítica de cinema do 
Suplemento Literário. Rio de Janeiro: Paz e

Terra; Embrafilme, 1981. (v. 1)

VANOYE, Francis; GOLIOT-LÉTÉ, Anne. Ensaio

sobre análise fílmica. Campinas: Papirus, 1994.

XAVIER, Ismail. 0 olhar e a cena: melodrama,

Hollywood, Cinema Novo, Nelson Rodrigues. São

Paulo: Cosac e Naify, 2003. 


\begin{tabular}{|c|c|}
\hline $\begin{array}{l}\text { Brazilian paranoid woman } \\
\text { films: The imagery of } \\
\text { the second women in } \\
\text { Brazilian horror movies }\end{array}$ & $\begin{array}{l}\text { Cine brasileño de mujeres } \\
\text { paranoicas: las Las imágenes de } \\
\text { las segundas mujeres en el cine } \\
\text { de terror brasilenõ }\end{array}$ \\
\hline $\begin{array}{l}\text { Abstract: } \\
\text { This article aims to discuss aspects of the horror } \\
\text { genre in five feature films made in Sao Paulo in } \\
\text { the } 50 \text { 's. These movies, inspired by what Mary Ann } \\
\text { Doane (1987) called "paranoid woman's films" } \\
\text { made in Hollywood in the 1940s, may have had } \\
\text { some influence on horror brazilian films, including } \\
\text { the seminal At midnight I'll take your soul (1964), } \\
\text { by José Mojica Marins, considered the first and } \\
\text { greatest representative of the horror genre in } \\
\text { brazilian cinema. } \\
\text { Keywords: } \\
\text { Brazilian Cinema. Woman films. Horror. }\end{array}$ & $\begin{array}{l}\text { Resumen: } \\
\text { Este artículo tiene como objetivo discutir los } \\
\text { aspectos del género de terror en cinco largometrajes } \\
\text { realizados en Sao Paulo em los anos 1950. Las } \\
\text { obras, inspiradas por lo que Mary Ann Doane } \\
\text { (1987) llama "películas de mujeres paranoicas" } \\
\text { de Hollywood de la década de 1940, pudo haber } \\
\text { tenido alguna influencia en las películas de terror } \\
\text { brasileñas más tarde, incluyendo la película seminal } \\
\text { A la medianoche tomaré tu alma (1964), del cineasta } \\
\text { y actor José Mojica Marins, considerado el más } \\
\text { grande representante del género terror em el cine } \\
\text { brasileño. } \\
\text { Palabras clave: }\end{array}$ \\
\hline
\end{tabular}




\section{Expediente}

A revista E-Compós é a publicação científica em formato eletrônico da Associação Nacional dos Programas de Pós-Graduação em Comunicação (Compós). Lançada em 2004, tem como principal finalidade difundir a produção acadêmica de pesquisadores da área de Comunicação, inseridos em instituições do Brasil e do exterior.

\section{E-COMPÓS I www.e-compos.org.br I E-ISSN 1808-2599}

Revista da Associação Nacional dos Programas de Pós-Graduação em Comunicação.

Brasília, v.14, n.1, jan/abr. 2011

A identificação das edições, a partir de 2008

passa a ser volume anual com três números.

\section{CONSELHO EDITORIAL}

Afonso Albuquerque, Universidade Federal Fluminense, Brasil Alberto Carlos Augusto Klein, Universidade Estadual de Londrina, Brasil Alex Fernando Teixeira Primo, Universidade Federal do Rio Grande do Sul, Brasil Ana Carolina Damboriarena Escosteguy, Pontifícia Universidade Católica do Rio Grande do Sul, Brasil

Ana Gruszynski, Universidade Federal do Rio Grande do Sul, Brasil Ana Silvia Lopes Davi Médola, Universidade Estadual Paulista, Brasil André Luiz Martins Lemos, Universidade Federal da Bahia, Brasil Ângela Freire Prysthon, Universidade Federal de Pernambuco, Brasil Angela Cristina Salgueiro Marques, Faculdade Cásper Líbero (São Paulo), Brasil Antônio Fausto Neto, Universidade do Vale do Rio dos Sinos, Brasil Antonio Carlos Hohlfeldt, Pontifícia Universidade Católica do Rio Grande do Sul, Brasil Antonio Roberto Chiachiri Filho, Faculdade Cásper Líbero, Brasil Arlindo Ribeiro Machado, Universidade de São Paulo, Brasil Arthur Autran Franco de Sá Neto, Universidade Federal de São Carlos, Brasil Benjamim Picado, Universidade Federal Fluminense, Brasil César Geraldo Guimarães, Universidade Federal de Minas Gerais, Brasil Cristiane Freitas Gutfreind, Pontifícia Universidade Católica do Rio Grande do Sul, Brasil Denilson Lopes, Universidade Federal do Rio de Janeiro, Brasil Denize Correa Araujo, Universidade Tuiuti do Paraná, Brasil Edilson Cazeloto, Universidade Paulista, Brasil Eduardo Peñuela Cañizal, Universidade Paulista, Brasil Eduardo Vicente, Universidade de São Paulo, Brasi Eneus Trindade, Universidade de São Paulo, Brasil Erick Felinto de Oliveira, Universidade do Estado do Rio de Janeiro, Brasil Florence Dravet, Universidade Católica de Brasília, Brasil Francisco Eduardo Menezes Martins, Universidade Tuiuti do Paraná, Brasil Gelson Santana, Universidade Anhembi/Morumbi, Brasil Gilson Vieira Monteiro, Universidade Federal do Amazonas, Brasil Gislene da Silva, Universidade Federal de Santa Catarina, Brasi Guillermo Orozco Gómez, Universidad de Guadalajara Gustavo Daudt Fischer, Universidade do Vale do Rio dos Sinos, Brasil Hector Ospina, Universidad de Manizales, Colômbia Herom Vargas, Universidade Municipal de São Caetano do Sul, Brasil leda Tucherman, Universidade Federal do Rio de Janeiro, Brasil Inês Vitorino, Universidade Federal do Ceará, Brasil Janice Caiafa, Universidade Federal do Rio de Janeiro, Brasil Jay David Bolter, Georgia Institute of Technology Jeder Silveira Janotti Junior, Universidade Federal de Pernambuco, Brasil João Freire Filho, Universidade Federal do Rio de Janeiro, Brasil
John DH Downing, University of Texas at Austin, Estados Unidos José Afonso da Silva Junior, Universidade Federal de Pernambuco, Brasil José Carlos Rodrigues, Pontifícia Universidade Católica do Rio de Janeiro, Brasil José Luiz Aidar Prado, Pontifícia Universidade Católica de São Paulo, Brasil José Luiz Warren Jardim Gomes Braga, Universidade do Vale do Rio dos Sinos, Brasi Juremir Machado da Silva, Pontifícia Universidade Católica do Rio Grande do Sul, Brasil Laan Mendes Barros, Universidade Metodista de São Paulo, Brasil Lance Strate, Fordham University, USA, Estados Unidos Lorraine Leu, University of Bristol, Grã-Bretanha Lucia Leão, Pontifícia Universidade Católica de São Paulo, Brasil Luciana Panke, Universidade Federal do Paraná, Brasil Luiz Claudio Martino, Universidade de Brasília, Brasil Malena Segura Contrera, Universidade Paulista, Brasil Márcio de Vasconcellos Serelle, Pontifícia Universidade Católica de Minas Gerais, Brasi Maria Aparecida Baccega, Universidade de São Paulo e Escola Superior de Propaganda e Marketing, Brasil

Maria das Graças Pinto Coelho, Universidade Federal do Rio Grande do Norte, Brasil Maria Immacolata Vassallo de Lopes, Universidade de São Paulo, Brasil Maria Luiza Martins de Mendonça, Universidade Federal de Goiás, Brasil Mauro de Souza Ventura, Universidade Estadual Paulista, Brasil Mauro Pereira Porto, Tulane University, Estados Unidos Nilda Aparecida Jacks, Universidade Federal do Rio Grande do Sul, Brasil Paulo Roberto Gibaldi Vaz, Universidade Federal do Rio de Janeiro, Brasil Potiguara Mendes Silveira Jr, Universidade Federal de Juiz de Fora, Brasil Renato Cordeiro Gomes, Pontifícia Universidade Católica do Rio de Janeiro, Brasi Robert K Logan, University of Toronto, Canadá

Ronaldo George Helal, Universidade do Estado do Rio de Janeiro, Brasil Rosana de Lima Soares, Universidade de São Paulo, Brasil Rose Melo Rocha, Escola Superior de Propaganda e Marketing, Brasil Rossana Reguillo, Instituto de Estudos Superiores do Ocidente, Mexico Rousiley Celi Moreira Maia, Universidade Federal de Minas Gerais, Brasil Sebastião Carlos de Morais Squirra, Universidade Metodista de São Paulo, Brasil Sebastião Guilherme Albano da Costa, Universidade Federal do Rio Grande do Norte, Brasil

Simone Maria Andrade Pereira de Sá, Universidade Federal Fluminense, Brasil Tiago Quiroga Fausto Neto, Universidade de Brasília, Brasil Suzete Venturelli, Universidade de Brasilia, Brasil

Valério Cruz Brittos, Universidade do Vale do Rio dos Sinos, Brasil Valerio Fuenzalida Fernández, Puc-Chile, Chile Veneza Mayora Ronsini, Universidade Federal de Santa Maria, Brasil Vera Regina Veiga França, Universidade Federal de Minas Gerais, Brasil

\section{COMISSÃO EDITORIAL}

Adriana Braga I Pontifícia Universidade Católica do Rio de Janeiro, Brasil Felipe Costa Trotta I Universidade Federal de Pernambuco, Brasil CONSULTORES AD HOC

Édison Gastaldo I Universidade Federal Rural do Rio de Janeiro, Brasil Gisela Grangeiro da Silva Castro, Escola Superior de Propaganda e Marketing, Brasil Helio Kuramoto, Instituto Brasileiro de Informação em Ciência e Tecnologia, Brasil Juliano Maurício de Carvalho, Universidade Estadual Paulista, Brasil Maria Helena Weber, Universidade Federal do Rio Grande do Sul, Brasi Paulo Carneiro da Cunha Filho, Universidade Federal de Pernambuco, Brasil Vera Regina Veiga França, Universidade Federal de Minas Gerais, Brasil EDIÇÃO DE TEXTO E RESUMOS I Susane Barros SECRETÁRIA EXECUTIVA I Juliana Depiné EDITORAÇ̃̃o ELETRÔNICA I Roka Estúdio
COMPóS I www.compos.org.br

Associação Nacional dos Programas de Pós-Graduação em Comunicação

Presidente

Itania Maria Mota Gomes

Universidade Federal da Bahia, Brasil

itania@ufba.br

Vice-presidente

Julio Pinto

Pontifícia Universidade Católica de Minas Gerais, Brasil juliopinto@pucminas.br

Secretária-Geral

Ana Carolina Escosteguy

Pontifícia Universidade Católica do Rio Grande do Sul, Brasil carolad@pucrs.br 